\title{
Between Form and Function History and Identity in the Blogosphere
}

\author{
LAURIE JOHNSON \\ UNIVERSITY OF SOUTHERN QUEENSLAND
}

'Blogs are fast becoming' is an apt start to any essay on the blogosphere, since blogs have indeed been fast becoming a good many things in recent years. In their attempt to survey the uses toward which blogs were being deployed less than a decade after the first blog went live, Axel Bruns and Joanne Jacobs noted in 2006 the incredibly diverse ways in which blogs had come to serve purposes beyond the intentions of individual bloggers: alternative news source that is seriously challenging mainstream media; powerful marketing tool for big businesses; essential election campaign strategy; and so on. ${ }^{1}$ Indeed, Bruns has elsewhere coined the term 'produsage' as a replacement for 'production' in coming to grips with the challenge of how to think of the process by which individuals can participate in blog culture when blogs appear to have become so readily co-opted by an industrial production model. 'Produsage' thus names the activities of those 'communities which engage in the collaborative creation and extension of information and knowledge.'3 This concept of 'produsage' represents an elegant solution to the problem of establishing a robust conceptual framework for understanding a phenomenon that has gone viral, in a cultural sense. The growth of the blogosphere has been such that even Technorati have ceased to offer reliable data on the numbers of blogs currently available, but estimates put the number of active blogs in 2010 in excess of 200 
million. ${ }^{4}$ This is from an on-line format that has been with us for little more than a decade. In a 2008 summary of the state of play in blog research, Geert Lovink observed that researching an object that is in a state of hyper-growth and permanent transformation' is nigh on impossible, but a theory of blogging can go beyond types of blogs or the vagaries of individual blogging practices to consider the field as an overarching process of 'massification'. 5 The question to which this essay will be addressed is this: whither individual identity in a cultural field defined by such massification? The formation of a general theory of blogging, as in the task to which Lovink has previously set himself, demands quite rightly that the thing itself 'cannot be separated from its output', 6 meaning the blogosphere is understood as the sum of its many parts. To seek to understand identity formation in the blogosphere, conversely, we would need to view the equation from the other side: to apprehend each and indeed every part in its relation to the larger sum.

The issue of identity has never been far from the concerns of internet researchers. Sherry Turkle claimed in her 1995 book, Life on the Screen: Identity in the Age of the Internet, that the internet marked a shift from protean selfconstruction to a 'saturated self,' undercutting a stable external reference pointethnic, national, social-for identity formation. ${ }^{7}$ Others, like Howard Rheingold, envisaged a somewhat more utopian potential for the emergence of vital virtual communities that would supplant the geographically bounded communities offline. ${ }^{8}$ It was characteristic of these earlier studies to maintain a distinction between online and off-line worlds; that is, between computer-mediated communication and the face-to-face varieties of interaction. Communications researchers have only begun to break free from this paradigm in recent years, ${ }^{9}$ but cultural historians and cultural studies researchers have long been eager to complicate the divide by exploring the ways in which the internet as a cultural formation reflects, intersects with, or disengages from other cultural and social formations. In relation to questions of identity, Daniel Punday and Lisa Nakamura, for example, were at the forefront of investigating the possibility for internet activity to reinforce ethnic identity, albeit at the risk of reinforcing ethnic stereotypes. ${ }^{10}$ Katherine Hayles and others examined issues of sexual identity on the internet, particularly in view of much of the hype over virtual sex and teledildonics.11 For each of the markers of identity typically studied by social scholars, to be sure, the late 1990s gave rise to 
studies of the ways in which those markers of identity were shaped in and by the internet and related phenomena. Yet it was symptomatic of the studies of that time to reach for overarching theoretical claims at the expense of specificity: studies of an internet relay chat (IRC) group or a multiple-user domain (MUD), for example, would form the basis of claims about the characteristics of the whole of 'cyberspace' or 'the internet' as catch-all categories. While these studies provided necessary correctives to the hyperbole that accompanied some earlier scholarship, I contend that by collapsing the divide between computer-mediated communication and faceto-face communication and replacing it with an overarching concept that speaks to a much broader cultural formation, the studies of the late 1990s and early part of the new century risked losing sight of what differentiates one form of internet activity from another and, as a consequence, how identity formation can differ from one to another. Since blogs emerged at about the same time internet researchers were in this phase of responding to earlier hyperbolic scholarship, there was also a risk that blog research would be caught up in the same drift toward the use of universal categories.

Studies still spring up from time to time that replicate this tendency, but over the past decade more studies have emerged that signal very clearly their wish to focus on specific formats. Fred Turner's From Counterculture to Cyberculture: Stewart Brand, the Whole Earth Network, and Digital Utopianism, for example, maps the history of the internet alongside countercultural movements of the 1960s and 1970s to show the Whole Earth 'Lectronic Link (WELL) and its offshoots on the World Wide Web (WWW) emerged when these two distinct histories converged as a form of mainstreaming of countercultures and also provided a way for technology borne of the American military complex to find a left-wing voice in the 1990 s. $^{12}$ Rather than drifting from a study of a specific format to make claims for the whole of the internet, then, Turner's work provides a model for drifting from a history of the internet to understanding the cultural meanings and uses of a specific format. A similar study of the history from which blogging emerged will, I propose, provide necessary insights into the nature of identity formation in the blogosphere. Such insights in no way constitute a grand theory of blogging; indeed, they run counter to the totalising goals of theory formation. I do not wish to provide a blanket description of the identity of a typical blogger, as if such a thing were possible. 
Instead, I propose that the history of blogging will help us understand how the form of blogs, which owes much to the long history of the internet, designates a specific kind of user, or produser, which in turn delimits the kinds of identities that can be formed with blogs. Perhaps more to the point, it helps us understand how individuals can form identities via blogs. Lest this be mistaken for a new brand of technological determinism, I suggest that the history of blogs also provides us with a way to reinscribe individual agency by allowing us to understand how a form that can be defined by produsage emerged out of a system forged within the postwar American military complex. I propose to use the term 'function' in opposition to form and separate from the notion of the use of something: by 'function,' then, I mean the properties and proper activities associated with the form. Identity formation in the blogosphere, I contend, must always be worked out by the individual, in the first instance, as a negotiation of this disjuncture between the form and function of blogs.

-BLOg FORMAT AND TYPICAL BLOGgERS

I suggest that consideration of form and function in the blogosphere will aid understanding the identities of bloggers precisely because it removes any explanatory role from the individual. This may seem counterintuitive. How can I explain individual identity by removing the individual from my explanatory framework? I think this is necessary only in the first instance because it removes the one guaranteed variable from our thinking just long enough to get a handle on the forces that work upon this variable in every instance. It is fair to assume that in any sample of bloggers, no two subjects will prove to be identical in a full list of uses and gratifications served by their blogging. Social researchers have, of course, attempted to identify trends in blog use. The oft-cited 2005 study by Dan Li, for example, showed that from seven categories of motivation presented, bloggers accepted 'selfdocumentation, improving writing, self-expression, medium appeal, information ... and socialization' as reasons for blogging, but widely rejected 'passing time' as a suitable motivation. ${ }^{13}$ Li's categories of motivation ignore a potentially infinite range of other uses, some of which overlap into the more corporate uses identified by Bruns, but also those that range from the merely whimsical (hobbies or sideinterests) to the sociopathic (the blogger-as-stalker). Similarly, studies of blogger 
demographics have been used to paint a picture of the 'typical blogger'. One 2005 study determined that 52 per cent of the blogosphere had been developed by teens from the thirteen to nineteen age bracket and that 56 per cent of bloggers were female. Of course, this simply means that the 'typical' teen female blogger made up a little over a quarter of the blogosphere-significant for blog researchers, but hardly typical. ${ }^{14}$ Such studies also miss the potential for variation across different cultural demographics. A 2006 study of Croatian bloggers showed that instead of a typically teen demographic, bloggers were by and large (88 per cent) aged between twenty and forty years, although a subsequent study by Marija Brala showed an overwhelming appeal among Croatian bloggers for Anglicised blogs. This suggests an ageing population could see blogging as a way to enter the global blog community, for which English is the dominant language of interaction. ${ }^{15}$ Similarly, the essays recently collected in International Blogging: Identity, Politics, and Networked Publics provide an array of vastly diverging accounts of the uses for which blogs are deployed in different locations around the globe, throwing into sharp relief the absurdity of the notion of a 'typical' blogger. ${ }^{16}$ Against this grain, then, I suggest that studies of blogger demographics, while valuable for developing a picture of the blogosphere from a social research perspective, do not altogether grasp a key problem for identity formation in the blogosphere: the one thing that all bloggers can be truly counted on to have in common is that they blog. Rather than seek to explain identity from the perspective of the individual, who from one sample to the next can differ enormously, then, I seek here to examine the prospect for identity formation that blogging makes available to the individual from the moment she or he chooses to blog, based on what the blog format brings into play in terms of its form and function.

While the blogosphere has grown exponentially in size, potentially proving to be a source of intimidation in and of itself for any would-be new blogger, the allure of the format remains its ease of use. Lovink points out, again quite rightly, that 'the blogosphere has been shaped neither by dotcom entrepreneurs nor by technogeeks. Basic computer knowledge does the job. Not even html skills are required.'17 A brief view of the kinds of arguments provided to the new user in popular guides bears this point out. Consider, for example, the definition of a blog in the Dummies book on blogging: 'Weblogs have a certain type of software running in the 
background ... Blog programs and ready-to-use blogging services cut out the laborious and technical traditional process of building a Web site.'18 The appeal of the blog is just this capacity to short circuit the labour intensiveness of web design and development, which even in the early boom years of the dotcom entrepreneurs and the rise of the 'homepage' proved to be a boon for those skilled in web design and a clear factor in the creation of a 'digital divide' in the 1990s. ${ }^{19}$ Yet Julie Meloni provides a comment on the nature of blogs, courtesy of this software which runs in the background, for the new blogger to consider: she begins her guide to blogging by advising any newcomers that their blogs will enable them to do whatever they want, so long as they want to participate in the 'greater blogging community', since, unlike a 'simple static website, the format of a blog creates a framework upon which a community can be built'. ${ }^{20}$ There is a hint in such a comment about the pre-existence of a digital divide for the novice blogger to consider even in the welcoming arms of the blogosphere: whosoever shall blog, the 'greater blogging community' already awaits. If blog software enables anybody to be a blogger, then we might surely expect that the 'greater blogging community' need not be an intimidating presence, imaginary or otherwise, since the novice blogger could be excused for thinking that such a community would be defined by the relative skill level of those who already blog. Blogging for Dummies has a full chapter in fact devoted to outlining the 'Rules of Blogosphere Citizenship' with some straightforward guidelines on blogger etiquette. ${ }^{21}$ To the prospective blogger, the corollary of starting a new blog is clear: once you click the post button you accept all the terms and conditions, including the condition that failure to adhere to these terms could be punishable by having your blog flamed back to the stone ages.

An important distinction needs to be made here. 'Blogging community' does not refer to a group of people who identify as a community on the basis of some shared interests or values, for which blogs are used to express points of commonality. 'Blogging community' refers to the community of bloggers: what they share is blogging. Communities of interest can be built up through blogs-this is the point that Meloni makes for the novice-because the format is community-oriented. For individual bloggers, there is perhaps a greater sense of belonging to a community that consists only of those who regularly post comments, follow blog posts, or even simply provide a link to their blog, rather than of belonging to a community 
comprising over two hundred million fellow bloggers. For many bloggers, as Lovink notes, the activity must seem a thoroughly isolated one-as the blogs for which zero comments are received might attest-and many blogs end up being sent to the blogosphere scrapheap with little more than residual archival presence to attest to their ever having existed.22 Lovink cites the example of 'Blogged Off', a blog that now exists solely in the form of the message to the effect that it is no more ... THIS IS AN EX-BLOG!!'23 Geoff Parkes, the ex-blogger in question, has continued to be active on the internet through a homepage, the Australian Public Intellectual Network and other activities, so the demise of 'Blogged Off' cannot be written off as the novice user failing to follow through on a whim. ${ }^{24}$ Indeed, the fact that an 'ex-blog' retains this residual presence suggests some kind of phenomenological slippage between the blogosphere and the 'blogging community': a blog need not at any moment signify the existence of an active and interested blogger at the keyboard. One piece of advice invariably given to novice bloggers is thus to 'post regularly,' since blog software foregrounds chronology and visitors to an inactive blog are unlikely to return. ${ }^{25}$ In addition to the communities of like-minded individuals that a single blogger may seek to write for, link to, comment on and so on, entry to the blogosphere seems nevertheless to insist on a somewhat more nebulous sense that by publishing one's blog, one is entering into a social contract with all other bloggers at least to the extent that these people are present to this contract in the form of all other blogs, active or inactive. Even the simplest of decisions in blog design-like whether to activate comments or not-involve some sense of how the blog (and therefore the blogger) will address itself to other bloggers and frame the capacity for their responses.

This nebulous sense of there being 'all other bloggers' is rendered more nebulous, I think, by virtue of the hyper-growth of the blogosphere which, by the time scholars started to study the phenomenon in earnest, already meant that we were bound to speak of it in terms of size and speed. History can help in this sense because it will mean a return to the point at which it becomes possible to ask: which came first, the blog or the blogging community? Answering what may seem at first to be an insoluble chicken-and-egg question-or what logic may state to be straightforward: community must come secondarily, after a critical mass of bloggers has been established-from a historical standpoint will, I suggest, provide us with a 
clearer sense of how the first blogs came into being, for what purpose, and for whom. The long history of blogging will show us that, indeed, the nucleus of the blogging community had existed first in the discussion forums of Usenet and that the development of blog software catered initially to the needs of Usenet users as they began migrating from Usenet to the World Wide Web. What hyper-growth has allowed to mutate into a nebulous sense of community once existed in very identifiable form as a group of techno-geeks wanting to stake their claims on the World Wide Web. The function of blog software, I suggest, is to render the complex structural form of the internet invisible from the perspectives of both blogger and reader, enabling the activities that were familiar to the Usenet community to be transformed for the imagined global readership of the Web. The resulting form-the typical features of the blog site-was always bound to be community oriented. While this means that bloggers can seek to form smaller communities with other like-minded individuals as subsets of the broader blogosphere, it also means that, in even some nebulous sense, a 'greater blogging community' has always existed as an external point of reference for every new blog and is thus a frame for identity formation of all bloggers as bloggers.

-BLOG PREHISTORY: ORIGINS OF THE INTERNET

As noted, Turner's account of the origins of the WELL and the Whole Earth Network is a model for the kind of history I wish to produce here. Blog history does not begin, that is, with the first blog, but must consider the longer history of the internet to which blogging belongs as a relatively recent development. Rather than rehearse this long history here, in the interests of space I will refer to several existing histories, Turner's included, but extract from them a number of key points that can be seen as crucial to the eventual development of blogs. Turner's history of the WELL, for example, begins with the emergence of the internet from the American military complex in the 1960s, along with an account of the degree of suspicion held in the wider American community about the dehumanising, militaristic nature of all new technologies at the time. ${ }^{26}$ In a similar vein, Janet Abbate's Inventing the Internet explores the social conditions that enabled technologies built by the US Department of Defense's scientific arm, the Advanced Research Projects Agency (ARPA), to become subsequently driven by the 'informal, decentralized, user-driven 
development' that characterised even the earliest phases of the internet proper. ${ }^{27}$ Neither Turner nor Abbate cling to a picture of the military portion of this history as purely militaristic, though. As Abbate neatly explains, while Cold War hysteria might have provided the motivation for the creation of ARPA, 'the group that designed and built ARPA's networks was dominated by academic scientists, who incorporated their own values of collegiality, decentralization of authority, and open exchange of information into the system'.28 Indeed, before Abbate and Turner, a brief history of the internet from the personal perspective of a collection of these academic scientists had been written down and recorded on the web. The history provided by Barry Leiner and his colleagues reads very much like a collegial account of the specific technical problems that early networking presented and how these problems were solved. ${ }^{29}$ Daniel Minoli and Andrew Schmidt expanded these technical arguments in their 1999 account of the structural growth of the internet, ${ }^{30}$ but Abbate clearly indicates a will to go beyond technical histories of the internet to consider the 'social shaping of computer communications', 31 a concern mirrored in Turner's exploration of counterculture and left-wing politics.

From these various histories, then, I wish to extract what I consider to be a number of the significant milestones or factors that make possible, perhaps even inevitable, the emergence of blogs. The first may seem so mired in the prehistory of blogs as to hardly warrant attention here, but its relevance will become clear as we progress. Between 1961 and 1968, a series of independent projects contributed to the development of what Donald Watts Davies, working for the National Physical Laboratory in Middlesex, England, called 'packet-switching.'32 In short, packetswitching enabled the construction of a more robust network than one built with a telephonic line, allowing information to be transmitted, carried, and reassembled with much greater precision than a traditional analog system. With the development of packet-switching, it became possible for remote computers to talk to each other. Of interest here is the way that these researchers came via different pathways to a convergent endpoint: Leonard Kleinrock, a doctoral candidate from MIT, had published some of his mathematical models in 1961; using some of Kleinrock's work, Paul Baran of the Rand Corporation had begun work on producing a communications system capable of surviving damage to any section of the grid in 1962; and from 1965 to 1968, Davies established a working application of his packet 
switching theory, a model that closely resembled those developed by Kleinrock and Baran. ${ }^{33}$ Rather than claiming any kind of proprietary rights on the knowledge and applications each of them had developed, these researchers proved content to share credit and continued to work on what was to become the ARPANET in 1969. Abbate points out that this 'chain of invention and dissemination has become a standard element of origin stories about the internet; indeed, it is easy to get the impression that packet switching simply took a detour through the United Kingdom before reemerging, unchanged, in the United States to fulfil its destiny as the underlying technology of the ARPANET.'34 Against this received history, Abbate details the policy environment under which each of these projects unfolded, revealing that Baran's work, for example, was a direct product of American Cold War paranoia, ${ }^{35}$ while Davies operated under the greater freedom of a government policy to increase resources for British researchers as a response to the 'brain drain' that had seen so many scientists flocking to resource-rich United States facilities. ${ }^{36}$ The watchword for Baran, building on Kleinrock's mathematical work, had been survivability; for Davies, it was interactivity. Packet-switching was not only a different solution to the problem of how to get computers to share data, which was then incorporated into the ARPA research; it also changed the mindset of the research. ARPANET would no longer simply be a way of getting data shared between different locations, increasing the chances of having information survive a nuclear strike; it could now be conceived by ARPA researchers as a communication technology in an interactive mindset.

In striving to portray the social construction of packet-switching, though, Abbate tends to downplay the extent to which this interactive mindset was already present within ARPA, by virtue of ideas both reported internally and published externally by Joseph Licklider, the head of the Information Processing Techniques Office (IPTO) within ARPA. Licklider nicknamed his research group the 'Intergalactic Network'37 in what was a precursor to the name given to the 'inter-net' when it later became a reality. He was interested in using computers to reshape communications completely, and he saw the development of the ARPANET as more than the interconnection of machines for the sake of improving the storage of information. His internal report on the ARPANET project reflected his desire for researchers to think beyond the idea of computers as 'arithmetic engines' and to imagine the 
emergence of new technologies for shaping human communities. ${ }^{38}$ Licklider published his research on 'man-computer symbiosis' throughout the 1960s, 39 in fact, and this work has been, as Tami Tomasello has demonstrated, much cited and influential in computer science research ever since. 40 Abbate's history gives to Licklider his due in a managerial sense but makes little of his vision for computer science, and indeed the discussion of the administrative structure of the IPTO in Abbate's book might even be read as an account of why Licklider's vision might have been diffused before it reached the scientists working on ARPANET, in spite of Abbate's consideration of the informal, collegial managerial style adopted by Licklider's underlings. ${ }^{41}$ Yet Licklider's influential publishing tells a different story, that this vision was being heard by his fellow scientists whether or not they were separated from him by the layered hierarchy of the Agency. The social construction of packet-switching is thus perhaps not as integral a factor as Abbate's history suggests, such that we might argue instead that interactivity was already present in Licklider's goals. Davies provided a specific technical solution to a problem faced by ARPA scientists, but by bringing his ideas into ARPA they did not add a new focus on interactivity that had been foreign to the project before then; rather, the interactivity promoted by Davies was well matched to a vision that already overarched the activities being undertaken within the IPTO.

The reader may wonder how this milestone feeds into the emergence of blogs in particular, and is not simply a quibble over the relative importance of a number of factors in play in the history of the internet writ large. Without Licklider's overarching vision, I suggest, there was no need for ARPANET to have been extended on the basis of what Bob Khan in 1972 called 'open architecture networking,' which refers to the principle that any packet switched network like ARPANET could be connected to any other network so long as protocols could be shared between them. ${ }^{42}$ Kahn's ideas extended the work of Davies to include the idea of connecting any number of networks together while still enabling each to operate its own functions (that is, at each terminal or on each machine within that individual network). The principle of open architecture networking was given the green light at DARPA - the acronym was expanded to include the ' $\mathrm{D}$ ' for 'Defense' in 1973-as a project under the name of 'internetting' and one of the project's most significant achievements was the establishment of host-to-host protocols, TCP/IP 
(Transmission Control Protocol/Internet Protocol), which remain a standard feature of the architecture of the internet more than three decades later.43 Open architecture networking is vital to the subsequent development of the internet because it was a principle of expansion: 'internetting' could now involve more than information sharing among a network of scientists within DARPA. ALOHANet was created as a packet radio network in 1970 and connected to ARPANET in 1972; Telenet was created by BBN in 1974 as the first commercial data packet service; demonstrations of a connection of three independent research networksARPANET, SATNET (the Atlantic Packet Satellite Network), and PRNET (the San Francisco Bay Packet Radio Network) - were made in 1977 using the new internet protocols; and in the early 1980s the proliferation of networks gained a new momentum, so by 1989, ARPANET had become such a peripheral component of the global internet that it was formally decommissioned and ceased operations altogether in 1990. The internet, as a global phenomenon that had outlived its progenitor, had arrived. Apart from a capacity for expansion, open architecture networking also generated an open-ended problem related to the question of functionality: from the very beginning, the challenge of networking had been to create interconnections between nodes or terminals while enabling each to maintain its specific, localised functions, but once a network was established, and once it connected to more networks, what additional functions could the network as a whole adopt? Those who developed ARPANET described the situation as they saw it with the first network of four computers in 1969: 'at this early stage, it should be noted that the networking research incorporated both work on the underlying network and work on how to utilize the network. This tradition continues to this day.' 44 What Barry Leiner and his colleagues are describing here is the establishment of a technology in need of a function of its own. Indeed, it was not until 1972, three years after ARPANET was first activated and the network had increased in size to 15 nodes across 23 servers that the first dedicated network application-electronic mail-was successfully developed. This search for functions for the broader network represents, I suggest, a crucial frame for the emergence of blogs for reasons that will soon be explained. 
One way to quantify the importance of a search for functions is to focus on what may seem a rather familiar distinction: computer technology traditionally separates the people who use it into two largely exclusive groups-programmers and users. Programmers create applications for users to use, but rendering the programming invisible to the user is of course a necessary marketing strategy. This strategy reinforces the notion that making something for a computer is a highly skilled task (programming) whereas doing something on a computer requires little or no specific competencies beyond being able to associate the movement of the hand with the movement of a cursor; for the user to follow the computer's instructions, shall we say, rather than the reverse. Frederick Hayes-Roth and Daniel Amor have argued that the next step in the evolution of information technology must be the adoption of a mantra of 'radical simplicity,' in which computers are designed and programmed to accommodate the needs of the user in a 'me-centric' fashion: the computer and its functionality accedes to each user's requirements. ${ }^{45}$ Such a mantra becomes relevant, of course, only where the programmer-user divide is seen to exist absolutely; to wit, deep within the heart of the home computing or PC revolution. This is a world constructed, as Bruns would remind us, around an old industrial production model. It is a feature of the blogosphere that production and use have become coterminous in the model of produsage. Blog software has enabled the digital divide posed by the first dotcom wave to be superseded. The World Wide Web was made possible by the development of hypertext mark-up language or HTML, which enabled links to be embedded within a document rather than requiring that the document be closed and a separate menu or directory be opened, and for the user to be able to activate the link directly via the hypertext within the document. The advent of HTML meant that website creation was the sole dominion of the web designer who was well versed in the language, just as programming had been the sole dominion of anybody trained in programming languages. Even userfriendly web design software has not overcome this hurdle for the layperson and few people with no HTML skills can say they have enjoyed trouble-free times in creating and uploading documents to the web. Since blog software puts the HTML component of website creation one step further behind the user-interface, which is 
template-based, the digital divide appears to dissolve and the user becomes the producer.

The proliferation of uses for which blogs have now become deployed, as outlined by Bruns and Jacobs and reiterated at the beginning of this essay, is a sign, I think, that blogs are also a form in search of new functions. Is this because blogs simply extend what is true of the whole of the internet? My answer to this would be no: most internet applications are themselves the products of a search for functions, answers to the question of what we can do with the internet once it was up and running. The World Wide Web is itself a function of the internet, simply a way of enabling document browsing to be managed more efficiently and within graphicsrich environments. Yet if the web had a 'me' on whom it was me-centred, it was still the producer and not the user. Web surfing was always about following only those pathways provided by a HTML-savvy digital elite. When I say that the search for functions for the internet involves a question of what 'we' can do with it, I refer to a pronoun in which producer and user cease to be separated. As Abbate rightly points out, mapping the early history of the internet involves crossing the divide "between narratives of production and narratives of use', because the first users of the new technologies were of course the first producers. ${ }^{46}$ My suggestion here is that the search for functions is an inevitable outcome of a situation in which producers are users, and it is possible to ask what might be done with the technology. This is the situation the pioneers in networking technology confronted once it became possible to expand beyond the defence network. The advent of blogging has, I suggest further, given a new generation of produsers the opportunity to ask the same question. Laurel Clyde has noted that once the fundamental structure of the blog was established, the blogosphere was bound to evolve rapidly, and to continue to do so in ways that cannot be predicted: 'the weblog scene is changing all the time, as new developments in technology make it possible for bloggers to do new things. Secondly, regardless of any definitions of blogging, bloggers will continue to test the boundaries of what is possible.' 47 Clyde's point is, first, that the surface features of blogs are constantly evolving as the underlying software undergoes refinements to meet the needs of bloggers, but also that the 'scene' and the very definition of blogging become fluid, driven by the bloggers themselves testing the limits of what can be done with the new form. 
If it seems that there is something of a parallel apparent at this point-that both the origins of the internet and the rise of the blogosphere bear witness to a moment in which the search for functions drives the development of particular forms - the remainder of this essay seeks to demonstrate that this is indeed no mere coincidence. Instead, I wish to establish that a history of the blog provides evidence of a direct lineage connecting the pioneering producer-users at ARPA to the makers of the earliest blogs. Turner's history of the WELL, another function of the internet, does not seek to establish such a direct lineage, nor should it. While he provides a relatively brief history of the internet emerging out of the American military complex, albeit with some consideration given to Licklider's man-computer vision, Turner's interest in the WELL means that he must take a detour away from internet history and engage with American counterculture of the 1960s to explain the origins of Stewart Brand's particularly liberal vision. The history of the WELL is thus the history of a form that was developed for the purpose of marrying the internet in corporatised fashion to American left-leaning politics. Blogs, as we shall see, emerge because the same people who were the earliest producer-users of the fledgling internet established the model copied by the next generation of producer-users (UNIX users) involving attempts to answer the question of the function of the network; this next generation are then directly responsible for spawning the blogosphere. Accordingly, then, we can confirm that the chicken and egg question does have an answer that seems to defy logic: a community of expert producer-users did in fact pre-exist the first blogs, and did indeed contribute to fashioning blogs as an extension of the search for functions.

\section{-A COMMUNITY OF PROD-USERS: ORIGINS OF USENET}

In logical terms, as I have suggested, surely in some primordial moment of first creation, in the beginning, there was blog, and it was good. After all, how could a community of bloggers have existed before there were blogs? The long history of the origins of blogs will tell us that a blogging community did indeed come first: its name was Usenet, and it too was good. The origins of Usenet can be seen as an attempt in 1979 by those in the broader group of networks outside ARPANET to mirror the producer-user activities of those inside ARPA. As we have seen, once ARPANET was up and running, those who worked on the network began to look for 
functions for the network, beyond the local uses to which each terminal or node was being put. While the core group of researchers initially conducted research team meetings in person, leading to significant delays between conferences, they soon agreed that ARPANET was itself a far more efficient medium for conducting discussions about ARPANET. The result was the establishment of the 'Request for Comments' (RFC) forum. An RFC was a post on any aspect of the internet project and, as the 'Documentation Conventions' listed in RFC-3 (April 1969) stipulated, 'Notes may be produced at any site by anybody and included in the series.' 48 This third RFC was the proof of a crucial facet of the RFC process: they were not merely technical posts but were intended instead to include all the research team's thought processes. RFC-3 stated even philosophical positions 'without examples or other specifics, specific suggestions or implementation techniques without introductory or background explication, and explicit questions without any attempted answers are all acceptable.' 49 Following the early example of RFC-3, there were subsequently a good many posts in the entire RFC sequence that were just of this kind, such as the yeoman effort produced in RFC-1000 (August 1987) to index all the previous 999 posts along with an introductory history of the RFC list by Steven Crocker, author of the first RFC and the creator of the documentation conventions. RFC-1336 (May 1992) included a 'Who's Who' list of contributors over the two decades of the RFC list, and Robert Braden of the Internet Activities Board included in his entry a reflection on the long-term success of the RFC model: 'The result was to create a community of network researchers who believed strongly that collaboration is more powerful than competition.' 50 We may take note here that RFC-1336 was posted in 1992, two years after ARPANET shut down. When ARPANET ceased operations, the RFC list was handed over to the Internet Society, such was the commitment of the researchers in question to the belief that their work was by this time too important to be allowed to die with the ARPANET project. By October 2010, the RFC list had surpassed six thousand posts. 51

Turner's history makes no mention of the RFC-list, since his history of the WELL has no need for the minutiae of ARPA technical operations. In its place, there are a good many fine details of the activities of Stewart Brand and his associates, and it is this level of detail that I wish to replicate here, but shifting our myopic attention to ARPA in the first instance, since we seek to establish a direct lineage between the 
blogging community and the origins of the internet. Abbate similarly disregards the RFC-list except in a few footnotes, as citations that support comments about the mindset of the researchers at ARPA. My reason for mentioning the RFC-list is to focus on the format itself, as a guide to the way these researchers carried out their research in a collaborative framework, but also because the RFC format was precisely an open-ended mechanism for conducting a search for functions: the answers to the question of what to do with an open architecture network were being worked out on the network itself. To Michael and Rhonda Hauben, the RFC model established a long tradition of collaboration and discussion, which would later be adapted and adopted by all subsequent online discussion and research forums, paving the way for what they saw as a global 'netizenry'.52 I tend to see the RFC-list in terms of a more delimited genealogy: RFC begat Usenet, which begat blogs. We should stop short, I believe, of extrapolating global trends from specific formats. By tracking a more precise genealogy, I suggest that we can gain a sense of some of the more systematic features inherited by a cultural form from its immediate precursors. About a decade after the RFC-list was established, as we have seen, ARPANET had been opened up to a number of additional external networks. One group who remained excluded by 1979 were the users of UNIX operating systems, since the institutions that housed the cheaper UNIX systems were also those that had no access to United States Defence funding, and UNIX had not therefore been adapted to TCP/IP networking protocols. Yet UNIX users were well aware of the work being done within ARPA on networking, given the licence that Licklider and his colleagues enjoyed in publishing their findings for the global scientific community to follow. Jim Ellis and Tom Truscott developed Usenet at Duke University in 1979 as a UNIX-based version of ARPANET.53

Truscott had been introduced to UNIX and its community of devotees while working over the summer of 1979 at Bell Laboratories, and became determined that his departure from Bell would not signal the end of his UNIX days. Together with Ellis, a fellow Duke graduate student, Truscott installed UNIX on a Duke computer and resolved to establish a dedicated network for UNIX machines alone. Another fellow student Stephen Daniel developed the first function of this network, the 'ANews' software based on a shell script created by Truscott and Ellis, which would enable networked computers to traffic posts categorised into specific newsgroups, 
and which-with the advantage of the UNIX operating system enabling software to timeshare and run multiple applications simultaneously-could check for incoming news posts while other tasks were being performed. Usenet went online with machines at Duke University and the University of North Carolina by the end of 1979, and within six months had expanded to eight nodes across several universities and, of course, Bell Laboratories. While Usenet enabled the UNIX enthusiast to exchange information on their favourite system about this system, thereby representing a viable and valuable producer-as-user reference and support mechanism, it also included newsgroups on any conceivable topic of interest to the community. As Truscott was an avid chess player and had in fact first learned of UNIX when his own chess program was defeated by one running on a UNIX system, it is no surprise that NET.chess was one of the earliest newsgroups on Usenet. ${ }^{54}$ From the outset, then, Usenet was modelled on the work being done by researchers at ARPA but with the added goal of utilising the extra functionality of the UNIX platform (its timesharing procedure), and thus represents a next generation of the RFC-list model. In early 1980, as Usenet was being promoted to the wider UNIX community, it was even hailed by its creators as 'the poor man's ARPANET'. 55

Each newsgroup within Usenet was indeed very much like an RFC-list, with the exception that posts-called 'articles' on Usenet-could address any topic of shared interest. Unlike the RFC-list, the origins of Usenet were tied to a specific platform rather than to the users of the specific network, ARPANET. I would argue that because the community was defined by use of a specific platform rather than a government-run project group, they were at liberty to exercise greater variety in the choice of topics, even though the RFC model is evident in the structure of Usenet. By 1981, connected sites increased to 50 and the number of newsgroups exceeded 100. Mindful of the potential proliferation of articles and users, Mark Horton of the University of California at Berkeley posted a proposal for a Usenet policy in October 1981:

USENET is a public access network. Any User is allowed to post to any newsgroup (unless abuses start to be a problem) ... The USENET map is also public at all times, and so any site which is on USENET is expected to make public the fact that they are on USENET, their USENET connections 
(e.g. their sys file), and the name, address, phone number and electronic address of the contact for that site for the USENET directory. ${ }^{56}$

Horton's proposal looks, in the first instance, very much like Crocker's RFC policy statement, inviting any user to post on any topic, but the statement that this is a 'public access network' crucially separates Usenet from ARPANET. While ARPA closely controlled and regulated all connections to its network, Usenet's software gave it scope to be a fully open access network. Anyone could connect to it from any UNIX operating system. Horton mandates open access in his opening claims, but he is also quick to protect the notion of community that underscores open access: anybody who connects to Usenet must fully disclose themselves. In other words, if you are in, you are in all the way for the duration of your connection.

- TWO MILESTONES: the FIRST BLog AND THE POST-BLOGgER BOOM

With the advent of Usenet, then, here was a network that was synonymous with the idea of a community of what we may now call produsers. Participation took place via posting articles and replies within newsgroups, each of which was populated by a number of subscribers, so no user was inundated with all of the articles being posted to all the newsgroups at any time. Each newsgroup was thus a subset of the broader Usenet community, and this community was defined further by adherence to a specific platform, and participation in Usenet-at least in its earliest years-also constituted testing of the limits of the UNIX system. Even as Usenet was launched, though, it came into contact with the network it sought in the first instance to rival. UNIX systems were added to the ARPA project in 1980, enabling ARPA researchers to gain access to Usenet, and by 1983 the UNIX system was also adapted to the TCP/IP protocols, so institutions reliant on UNIX systems were able to connect to ARPANET and vice versa. The greater flexibility built into Usenet, as well as the strong community basis on which it was by that time well established, ensured its continuation. Indeed, so successful has Usenet been that in spite of the advent of the World Wide Web, it has remained operational with over 110,000 functioning newsgroups listed at Allthenewsgroups.com. While the web offers users a more engaging visual interface, dedicated users of Usenet maintain a preference for the newsreader interface which does not require a graphical web browser and its attendant risk of commercial interruptions such as pop-up advertising, banners and 
so on. Yet the first ever blog could be described as one Usenet user's attempt to bridge the two platforms. In December 1997, Jorn Barger announced in an article posted to several newsgroups that he was going to create his own web page in which he would maintain a record of his web surfing activity, listing the sites to which he linked and posting a brief commentary about each of them. ${ }^{57}$ Barger called this site a 'weblog' since it would consist of a log of his web travels, but he did not invent the term, which was previously used for an automatically generated log of activity on any web server. According to Dennis Jerz, though, Barger's announcement was sufficient to prompt the computing community en masse to adopt the term 'server log' for a web server log, thus paving the way for the term 'weblog' to be adopted for the purposes of referring to a web site consisting of any log of personal activity.

Some histories of blogging also suggest that Barger's weblog was not the first of its kind but was merely the first to use this name for this purpose. Jerz observes that among the first ever sites on the World Wide Web was a list of all new websites as they came online. Yet unlike this straightforward directory of websites, Barger's log gave a personal commentary on the sites it logged, and these commentaries were not intended to be an aid to prospective fellow web surfers by way of some assessment of each site. Julian Dibbell points out that Barger's observations were intended to be just that: his observations. ${ }^{58}$ Dibbell describes Barger's early career in psychology and his belief that a map of a person's mind could be created by locating patterns in their behaviour, such as from their writing. ${ }^{59}$ In Dibbell's words, Barger's weblog was to be a self-portrait, his stamp of himself on the World Wide Web:

As intense as his netnews involvement was, though, Barger felt something was missing-a context for his postings, some frame of reference that would fill in the contours of his Net persona, now badly fragmented across the boundaries of his various newsgroups. His weblog, in the end, was born to fill that need. 60

Jerz also notes that sites before Barger's contained commentaries about sites and journals of web surfing activity. In what way could we say that Barger's site constituted the first weblog if others just like it were already included on the web? We already have our answer to this question: Barger's weblog was unlike other sites inasmuch as it identified as a weblog to a community of users intended to accept it 
as such. Barger's announcement was not a farewell to the Usenet community; it served as an invitation, a spur. While only a few sites of this kind can be shown to predate Barger's weblog, a significant number of new weblogs, identified as such by their creators, sprang up during 1998. By November, Cameron Barrett published a list of 'other sites like his,' compiled by Jesse James Garrett, and the number was at that time twenty-three.61 Barger's announcement to his Usenet peers was surely a catalyst for the emergence of these new weblogs. Certainly, the sites defined as weblogs displayed a number of the characteristics of the old netnews message system: a date stamp for each entry, reverse chronological order and categorisation of articles, for example. Into 1999, weblog proliferation continued apace, and those who compiled lists of weblogs found it difficult to keep updated. The list on Barrett's CamWorld ceased to claim to be a comprehensive list, offering only a list of sites that Barrett himself visited regularly. The first authoritative list, Brigitte Eaton's Eatonweb Portal, restricted itself to only those sites that used dated entries. ${ }^{62}$ Already, the rules about what could and what could not be called a weblog were beginning to form among the first participants, in debates from which Barger himself tended to be rather aloof.

In little more than twelve months from Barger's announcement that he had set up the first weblog, a blogging community had emerged. My sense of this sudden growth is of course that the nucleus of this new community had already existed as subscribers to the newsgroups in which Barger made his announcement on Usenet. Despite some of the debates about what types of sites warranted being called weblogs, there is clear evidence that a sense of a shared or communal practice did exist among these earliest bloggers. In April 1999, Peter Merholz announced on his weblog that he had decided to pronounce weblog as 'we blog' and from this moment the term 'blog' for weblog and 'blogger' for the writer of a weblog entered into the vernacular, a process that has been subsequently reflected, as Robert Glenn Howard argues, in the way in which bloggers have contributed to the emergence of a new language of the web. ${ }^{63}$ Merholz's first blog-specific web pun was made possible, of course, by the fact there was the communal 'we' already engaged in this activity. Merholz had an audience, and every member of his audience in turn had an audience of their own, and so on. This was a community that identified itself in terms of what all of these people saw themselves doing in a truly collective sense: we blog. 
Importantly, this community was not an entity that could be wholly identified with a single member. Like an expanding collection of newsgroups, the blogging community was already an amalgam of smaller cohorts, each member of which closely followed a small number of other blogs but none of whom knew every other blog in existence. A blogosphere that exceeded the individual uses and smaller chains of associations had emerged before the word 'blog' had even been attached to it.

It is also important to remember that in this early period during which the blogging community acquired credence, blog creation still required specific knowledge of HTML and web editing skills. The first do-it-yourself weblog tool Pitas was not launched until July 1999 and Blogger, by far the most successful blogging software package, was not launched until a month later. ${ }^{64}$ Rebecca Blood noted in 2002 , only a few years later, that these new tools transformed the genre of blogs almost overnight. The original blogs, modelled on Barger's log of activities, were 'link-driven sites ... a mixture in unique proportions of links, commentary, and personal thoughts and essays'.65 Yet, 'in the post-Blogger explosion increasing numbers of weblogs eschewed this focus on the Web-at-large in favour of a sort of short-form journal'.66 Blogger had made such a transformation possible because its simple interface places emphasis on simple text entry, easily recognisable as a sort of reversion to the textual interface that had been championed by Usenet users. Suddenly, it was possible for anybody to create their own blog, regardless of their technical proficiency. It was not long before bloggers with no HTML proficiency outweighed the number of those who had constructed their sites manually. These blog software packages included one feature that prevents us, though, from imagining that the proliferation of blogs by laypersons transformed the blogging community into a morass of dullards. The blog creation interface automatically generated within each blog the facility for visitors to comment on each post. Not only was the ability to post new content made easier for the blogger, the blog now automatically functioned like a 'request for comments'. Thus, for a generation of new bloggers, using blogging software rather than conventional HTML, there is an inbuilt sense of the community of already expert users or produsers. To blog is therefore to enter into open dialogue, which means that if anything blogging software actually brought blogging closer to the functionality of Usenet and its 
immediate precursor, the RFC-list. The 'blogging community' is not, however, any longer coterminous with the Usenet cohort from which the blogosphere first sprang, as blogging software kick-started the potential for hyper-growth that now renders impossible any tangible sense of community. What remains is simply a residue of what once existed as a new-wave Usenet beyond the UNIX platform.

\section{-CONCLUSION}

In a short essay on blogging written for fellow librarians in 2006, Michelle Young tried to allay any fears or hyperbole about the hyper-growth of the blogosphere by reassuring readers that blogging was simply the old pastime of journal or diary writing updated to a new medium for the electronic age. ${ }^{67}$ Codex still rules, okay? If such claims were true, at least in the direct manner in which they are expressed in essays like Young's, then blogging could never fully be described as a search for functions. Rather, it would simply be the transposition into a new medium of much older, seemingly ubiquitous, functions of a more general condition that may be called 'being human'. Even as the basis of such claims rests in reaching back to a pretech world of solitary, handwritten journals, history in fact provides a necessary argument against what amounts to a resistant anti-utopian hyperbole. As I have argued here, blogging emerges historically at the moment that one Usenet produceruser (or produser) made the decision to carry across the search for functions from the UNIX platform to the World Wide Web. What was needed on the web, to Barger, was a facility for engaging with the web in a manner that was suited to the production-as-use focus of Usenet. Once blogs had become established, and their appeal was obvious, blog software enabled the 'massification' to which Lovink referred, but it never altogether removed the techno-geeks from the equation. It is a historical fact that the first computer users were also the first techno-geeks, and I suggest that there remains in the 'blogging community' with which all bloggers identify upon entry to the blogosphere a residue of this fact: to engage in blogging is to actively identify as a blogger. Studies that explain identity formation only in terms of the use of the technology to facilitate a particular version of one's self overlook an important aspect of identity formation in the blogosphere. One does not blog to fashion an identity; one is a blogger. Rather than think of blogs as a new form of website, furthermore, the origins of blogs out of Usenet should serve as a signal that 
blogs are, in fact, another extension of the 'poor man's ARPANET', which is to say that blogs have always been a new layer of the internet-a new network in their own right-created like the first networks in a climate of searching for new functions for this new network. When one identifies as a blogger, in other words, one is also identifying with the principles from which the first networks were forged, chief being the idea of open architecture, the endless potential for the addition of new nodes to the network and, as Clyde had observed, testing the boundaries. The blogger is, in this sense, also already a researcher into the limits of blogs, as opposed to a user imagined in an old world model of industrial production as adhering to the established form (and the already defined uses) of a specific technology. The search for new functions is therefore, by extension, a search for new identities made possible in relation to a form that remains open and evolving.

Laurie Johnson is associate professor of English and Cultural Studies and a member of the Public Memory Research Centre at the University of Southern Queensland. He is author of The Wolf Man's Burden (2001) and co-editor of Rapt in Secret Studies: Emerging Shakespeares (2010), as well as author of articles and chapters on cultural theory, cyber studies, Early Modern studies, ethics, literary theory, psychoanalysis and related areas.

-NOTES

${ }^{1}$ Axel Bruns and Joanne Jacobs. 'Introduction', in Axel Bruns and Joanne Jacobs (eds), Uses of Blogs,

Peter Lang, New York, 2006, pp. 1-9.

2 Axel Bruns, Blogs, Wikipedia, Second Life, and Beyond: From Production to Produsage, Peter Lang, New York, 2008.

3 Bruns, p. 2.

${ }^{4}$ Lee Hopkins, 'Technorati and the Size of the Blogosphere: It Can't be THAT Hard to Figure Out, Surely?!' Lee Hopkins.net, 26 December 2009, <http://www.leehopkins.net/2009/12/26/technoratiand-the-size-of-the-blogosphere-it-cant-be-that-hard-to-figure-out-surely/>.

${ }^{5}$ Geert Lovink, Zero Comments: Blogging and Critical Internet Culture, Routledge, New York and London, 2008, p. xxiii.

${ }^{6}$ Lovink, p. 4. 
${ }^{7}$ Sherry Turkle, Life on the Screen: Identity in the Age of the Internet, Simon and Schuster, New York, 1995, pp. 180-2.

${ }^{8}$ Howard Rheingold, The Virtual Community: Homesteading on the Electronic Frontier, Addison-Wesley, Reading, Massachusetts, 1993.

9 Laurie Johnson, 'GUI Faces, Sticky Ethics', Transformations, vol. 18, 2010.

<http://www.transformationsjournal.org/journal/issue_18/article_03.shtml>.

10 Daniel Punday, 'The Narrative Construction of Cyberspace: Reading Neuromancer, Reading Cyberspace Debates', College English, vol. 63, no. 2, 2000, pp. 194-213; Lisa Nakamura, Cybertypes: Race, Ethnicity, and Identity on the Internet, Routledge, New York, 2002.

${ }^{11}$ N. Katherine Hayles, How we became Posthuman: Virtual Bodies in Cybernetics, Literature, and Informatics, University of Chicago Press, Chicago, 1999.

12 Fred Turner, From Counterculture to Cyberculture: Stewart Brand, the Whole Earth Network, and Digital Utopianism, University of Chicago Press, Chicago, 2006.

13 Dan Li, Why Do You Blog? A Uses and Gratifications Inquiry into Bloggers' Motivations, Masters thesis, Marquette University, 2005.

14 David A. Huffaker and Sandra L. Calvert, 'Gender, Identity, and Language Use in Teenage Blogs', Journal of Computer-Mediated Communication, vol. 10, no. 2, 2005 <http://onlinelibrary.wiley.com/doi/10.1111/j.1083-6101.2005.tb00238.x/full>.

15 Marija Brala, 'Language, Policy, and Identity: Perceptions of and Expectations for (Non)anglicized Language on the Web. The Case of Croatian Blogs', Bulletin suisse de linguistique appliqué, vol. 87, no. 3, 2008, pp. 73-94.

${ }^{16}$ Adrienne Russell and Nabil Echchaibi, (eds), International Blogging: Identity, Politics, and Networked Publics, Peter Lang, New York, 2009.

17 Lovink, p. 4.

18 Brad Hill, Blogging for Dummies, Wiley Publishing, Indianapolis, 2006, pp. 10-11.

${ }^{19}$ Pippa Norris, Digital Divide: Civic Engagement, Information Poverty, and the Internet Worldwide, Cambridge University Press, Cambridge, 2001, pp. 3-25.

20 Julie C. Meloni, Blogging in a Snap, Sams Publishing, Indianapolis, 2006, p. 3.

21 Hill, pp. 267-81.

22 Lovink, pp. 36-8.

${ }^{23}$ Lovink, p. 37. The URL, uncited by Lovink, is: <http://home.iprimus.com.au/laurapalmer/blog.htm>.

${ }^{24}$ At the time of writing, Geoff Parkes is employed at the University of Southern Queensland, and commented directly.

${ }^{25}$ Nora Ganim Barnes, 'Behind the Scenes in the Blogosphere: Advice from Established Bloggers,'

Report, University of Massachusetts Dartmouth Centre for Marketing Research, n.d.

<http://www1.umassd.edu/cmr/studiesresearch/cmrblogstudy.pdf>.

26 Turner, pp. 28-9. 
27 Janet Abbate, Inventing the Internet, MIT Press, Cambridge, Massachusetts, 2000, p. 4.

${ }^{28}$ Abbate, p. 5.

${ }^{29}$ Barry M. Leiner, Vinton G. Cerf, David D. Clark, Robert E. Kahn, Leonard Kleinrock, Daniel C. Lynch, John Postel, Lawrence G. Roberts, and Stephen S. Wolff, 'A Brief History of the Internet, Version 3.32', Internet Society (ISOC), 2003 <http://www.isoc.org/internet/history/brief.shtml>.

30 Daniel Minoli and Andrew Schmidt, Internet Architectures, John Wiley \& Sons, New York, 1999.

31 Abbate, p. 4.

32 Minoli and Schmidt, pp. 12-14.

33 Minoli and Schmidt, pp. 12-14.

${ }^{34}$ Abbate, p. 8.

35 Abbate, pp. 8-20.

${ }^{36}$ Abbate, pp. 21-33.

37 Michael Hauben and Rhonda Hauben, Netizens: On the History and Impact of Usenet and the Internet, IEEE Computer Society Press, Los Alamitos, California, 1997, p. 97.

38 Hauben and Hauben, pp. 97-9.

39 J.C.R. Licklider, 'Man-Computer Symbiosis,' IRE Transactions on Human Factors in Electronics, no. 1, 1960, pp. 4-11; J.C.R. Licklider and Welden E. Clark, 'On-line Man-Computer Interaction', AIEE-IRE '62 (Spring) Proceedings of the May 1-3, Spring Joint Computer Conference, ACM, New York, 1962, pp. 11328; J.C.R. Licklider, 'Man-Computer Partnership', International Science and Technology, no. 41, 1965, 18-26; J.C.R. Licklider, Libraries of the Future, MIT Press, Cambridge, Massachusetts, 1965.

40 Tami K. Tomasello, A Content Analysis of Citations to J.C.R. Licklider's 'Man-Computer Symbiosis,' 1960-2001: Diffusing the Intergalactic Network, PhD Thesis, Florida State University, 2004.

41 Abbate, pp. 54-61.

42 Minoli and Schmidt, p. 19.

43 Leiner et al.

44 Leiner et al.

45 Frank Hayes-Roth and Daniel Amor, Radical Simplicity: Transforming Computers into Me-centric Appliances. Prentice-Hall, Upper Saddle River, New Jersey, 2003.

46 Abbate, p. 4.

47 Laurel A. Clyde, Weblogs and Libraries, Chandos Publishing (Oxford) Limited, Oxford, 2004, p. 3.

${ }^{48}$ Hauben and Hauben, p. 106.

49 Hauben and Hauben, p. 106.

50 Hauben and Hauben, p. 107.

51 L. Berger, 'RFC-6004: Generalized MPLS (GMPLS) Support for Metro Ethernet Forum and G.8011

Ethernet Service Switching', IETF, October 2010 <http://datatracker.ietf.org/doc/rfc6004/>.

52 Hauben and Hauben, p. 107.

53 Hauben and Hauben, pp. 161-70. 
54 Hauben and Hauben, p. 167.

55 Hauben and Hauben, p. 41.

56 Hauben and Hauben, p. 175.

57 Dennis G. Jerz, 'Vannevar Bush, Weblogs, and the Google Galaxy', Dichtung-digital, no. 27, 2003,

$<$ www.dichtung-digital.org/2003/1-jerz.htm>.

58 Julian Dibbell, 'Portrait of the Blogger as a Young Man,' in John Rodzvilla (ed.), We've Got Blog: How Weblogs are Changing our Culture, Perseus Publishing, Cambridge, Mass., 2002, pp. 69-77.

59 Dibbell, p. 74.

60 Dibbell, p. 75.

${ }^{61}$ Rebecca Blood, 'Weblogs: A History and Perspective', in John Rodzvilla (ed.), We've Got Blog: How Weblogs are Changing our Culture, Perseus Publishing, Cambridge, Mass., 2002, p. 7.

62 Blood, p. 8.

${ }^{63}$ Robert Glenn Howard, 'Electronic Hybridity: The Persistent Processes of the Vernacular Web',

Journal of American Folklore, vol. 121, no. 480, Spring 2008, pp. 192-218.

64 Blood, p. 8.

65 Blood, p. 8.

66 Blood, p. 10.

67 Michelle L. Young, 'Blogging: An Introductory Look at an Old Pastime in a New Medium', Library Hi-

Tech News, no. 8, 2006, pp. 27-8. 